\title{
Integrated software package for simulation simulator - Grapher - 2D and 3D surfer representation verification and validation
}

\author{
Ahmed Najim Nimir Al - Subeeh \\ Computer Science, Shatt Alarab College University, Ministry of Higher Education and Scientific Research, Iraq
}

Article Info

Received, 2019

\section{Keyword:}

Tiger 2000,

Simulation,

Surfer,

Grapher,

Software Package

\section{Corresponding Author:}

Author,

Computer Science,

Shatt Alarab College University,

Ministry of Higher Education and Scientific Research, Iraq

Email: Ahmed_nimir@yahoo.com

\begin{abstract}
Simulation is one of the most important tools of engineering science. In this research an integrated engineering software package was designed to simulate oil reservoirs as an efficient tool which simplify the simulation process and provides the most requirements during the data entry, simulation of the reservoir, and till to reporting and documentation stage. The proposed package is capable to conduct analyzes and drawings in two or three dimensions with animated three dimensional virtual view which is most important feature. This integrated software package named Tiger 2000 can be used for any reservoir, whatever the geometric shape it represents. The 2000 Tiger can handle all operations that may occur in the reservoir such as production or injection as well as the water invasion of the reservoir. A number of engineering and software technologies have been used to accomplish this package, including Open GL, Visual Basic, FORTRAN Power Station, and Visual C. The integrated software package Tiger 2000 consists of five sub-packages: Simulator, Grapher, 2D and 3D Surfer for surface representation, 3D representation, representation of reservoir, aquifer and well sites as well as "Reservoir Show" which is an animated view of the simulated zones. The proposed software package in the current study is directly draw and represent the processed data and output results which is simplify the error detection, simulation and decision making for current and future reservoir processing and developments. This software package is the first of its kind designed in Iraq and the Arab world, where as all the calculations of oil and reservoir studies using ready-software purchased from foreign countries and costs up to millions of dollars. Although this is the first version of Tiger 2000, it is a big and very promising step towards Middle Eastern scientific software that serves scientific and engineering applications. Tiger 2000 can also be used even in simulating groundwater reservoirs and thus provides another service in the extraction and management of groundwater, especially as the abundance of water has become a top concern at all levels.
\end{abstract}

\footnotetext{
Email: Ahmed_nimir@yahoo.com
} 


\section{Introduction}

Simulation is one of the important engineering and scientific tool which becomes an essential and reliable to be used in wide variety applications. Appropriate and good simulation saves effort and time in studying and analysis and gives greater opportunity to make better decisions. In engineering reservoirs, simulations are clearly involved in the management of field operations and oil and gas production. Underground fluid flow is represented in porous media by complex mathematical models starting by derivation of what is known as diffusivity equation for each flowing fluid phase. The complexity is depending on the nature of fluids flow, porous media, shape of reservoir, and surrounding medium. These complex models are transformed into numerical and software models so that they can be solved by sophisticated computers. The engineer in charge needs to make very large data entry covering the details of the reservoir under study. The size of the data grows with the largeness of the reservoir and the complexity of its geometric shape as well as flowing fluids. Data also increased and complicated as the required accuracy and detail increased. After the data is entered, the following stages begin (1):

A. Checking the data entered.

B. Correcting erroneous data (data verification).

C. Simulator verification during no flow steady state.

D. Simulator validation during which the past recorded history from field measurements are matched the simulator output results.

E. Start conducting future simulations and according to the suggested plans.

F. Analyzing the results and draw them on different axes from different views to conclude the right decisions.

G. Reporting and documentation.

Depending on the above discussion, it is clear that there are wide challenging and complex issues that facing the engineers in charge. In the current study, an integrated software package called Tiger 2000 is designed to accomplish all these engineering requirements beginning with data entry, simulation, graphics, representation, and reporting in one package. Tiger 2000 contains six sub-packages:

H. Simulator.

I. Grapher.

J. Two dimensional Surfer.

K. Three dimensional representation surfer.

L. Representation of reservoir, aquifer, and well locations in an animated reservoir show.

M. Documentation and reporting package.

N. Some details will be presented below.

\section{Engineering information and specifications}

The proposed software package in the current study was programmed and designed using several different software programming platforms. Advanced level of visual BASIC language (3) and visual C language (4) as well as Microsoft FORTRAN Power Station. $(5,6)$ These different programming platforms are connected by using what is known as mixed language programming. (7,8) Mixed language programming allows the different functions and procedures to interact with each other making unified software platform. Also the theories of computer graphics $(9,10)$ and OpenGL (11) are involved in the current proposed software package. The detail of programming and software structures are introduced in a separated work. The current engineering software package is capable to process and treat the following issues and problems:

\section{A. Reservoir Geometry Geometry:}

1. One-dimensional reservoir processing (1D). 
2. Two dimensional reservoir processing (2D).

3. Three dimensional reservoir processing (3D)

B. Fluids and Number of Phases:

1. Treatment of single-phase flow (oil or water).

2. Treatment of two phase flow (oil and water).

A. Field operations:

1. Production processes with different perforation manners.

2. All types of injection processes.

3. Peripheral or marginal water invasion.

A. Auto-sensing of delta time $(\Delta t)$ length during simulation process.

B. Direct auto-correlation between input data and calculated results simply and effortlessly.

C. Auto-drawing of pressure and production data with time and according to suggested plans.

D. Auto-representation of pressure data - saturation - rock properties - and the most depleted zones in the form of two-dimensional colored surfaces.

E. Auto-representation of pressures, production, saturation and rock characteristics data through threedimensional colored drawings with control of vision settings, view magnification and rotation direction.

F. Three dimensional animation representations of the reservoir, aquifer, and well locations.

G. Performing all printing and reporting all output results and analyzes to be documented.

\section{Simulator}

The Black Oil simulation model is designed in three dimensions compressible fluid two phase flow (oil-water) called modified Tiger 2000 simulator. Capillary forces and gravity were taken into consideration in addition to the rock compressibility. ${ }^{(12,13,14)}$ The design method of the model in the current study makes it a general model for various reservoir studies without any change or modification in the main program. Tiger 2000 simulator is able to handle the fluids flow in the following cases:

A. One dimension fluid flow (1D) such as horizontal flow, vertical flow or inclined flow.

B. Two dimensional fluid flow (2D) such as $(x-y)$ or $(x-z)$.

C. Three dimensional fluid flow (3D) (x-y-z).

D. The compressible flow in single phase (water, oil, or mixed).

E. Multi-phase compressible fluid flow (water and oil).

Another important feature is the ability of the modified Tiger 2000 model to handle the presence of more than one type of oil in the same reservoir. It is also capable to treatment of more than one type of reservoir rock types and capillary forces in the same reservoir without any modification or adjustment in the main program. Tiger 2000 simulator generates the following data:

A. Arial and volumetric pressure distributions.

B. Arial and volumetric saturation distributions of oil and water.

C. The important contour maps in the study of the reservoir such as:

1. Contour maps for the distribution of pressures.

2. Contour maps for the distribution of saturations.

3. Contour maps for permeability distribution.

4. Contour maps for the distribution of porosity.

5. Contour maps for the distribution of porosity - thickness.

6. Contour maps for the distribution of permeability - thickness.

The main diffusivity equations used are: $(12,13,14)$ 


$$
\begin{aligned}
& \frac{\partial}{\partial x}\left[\lambda_{W X}\left(\frac{\partial P_{W}}{\partial x}-\gamma_{W} \frac{\partial h}{\partial x}\right)\right]+\frac{\partial}{\partial y}\left[\lambda_{w y}\left(\frac{\partial P_{W}}{\partial y}-\gamma_{w} \frac{\partial h}{\partial y}\right)\right]+\frac{\partial}{\partial z}\left[\lambda_{w z}\left(\frac{\partial P_{W}}{\partial z}-\gamma_{W} \frac{\partial h}{\partial z}\right)\right]+\tilde{q}_{W}=\frac{\partial}{\partial t}\left[\phi S_{W} \cdot b_{W}\right] \\
& \frac{\partial}{\partial x}\left[\lambda_{O x}\left(\frac{\partial P_{o}}{\partial x}-\gamma_{o} \frac{\partial h}{\partial x}\right)\right]+\frac{\partial}{\partial y}\left[\lambda_{O y}\left(\frac{\partial P_{o}}{\partial y}-\gamma_{o} \frac{\partial h}{\partial y}\right)\right]+\frac{\partial}{\partial z}\left[\lambda_{O z}\left(\frac{\partial P_{o}}{\partial z}-\gamma_{o} \frac{\partial h}{\partial z}\right)\right]+\widetilde{q}_{o}=\frac{\partial}{\partial t}\left[\phi S_{o} b_{o}\right] \\
& \text { where: } \\
& \lambda_{W X}=\frac{K_{X} \cdot K_{r w} \cdot b_{W}}{\mu_{W}} \\
& \lambda_{O X}=\frac{K_{X} \cdot K_{r o} \cdot b_{O}}{\mu_{O}} \\
& \lambda_{W Y}=\frac{K_{Y} \cdot K_{r w} \cdot b_{W}}{\mu_{w}} \\
& \lambda_{O Y}=\frac{K_{Y} \cdot K_{r o} \cdot b_{O}}{\mu_{O}} \\
& \lambda_{W Z}=\frac{K_{Z} \cdot K_{r w} \cdot b_{W}}{\mu_{W}} \\
& \lambda_{O Z}=\frac{K_{Z} \cdot K_{r o} \cdot b_{O}}{\mu_{O}}
\end{aligned}
$$

More detail about the diffusivity equation can be found in references $(12,13,14)$.

From the figures 4, 5, 6 and 7, there are much important information that makes the reservoir engineer fully informed of the processes going on during the simulation phase. This information includes:

A- Static Simulation Period in which the so-called Initialization is achieved and in which the initial distribution of pressures and saturations is achieved at the beginning of the reservoir discovery life. The Initialization process at modified Tiger 2000 Model is based on an efficient method first presented as new efficient method for reservoir initialization. (14)

B- Dynamic Simulation Period, in which the actual simulation of the reservoir begins with its injections, production suggested plans and water invasion.

C- Simulation of the surface of oil-water contact, which has a reservoir pressure rate and control point, coordinates to check the results.

D- Number of wells produced.

E- Number of injected wells.

F- The amount of oil produced.

G- Amount of water produced.

$\mathrm{H}$ - Amount of water injected.

I- Information on the current delta time $(\Delta t)$, the number of repetitions and the time it consumed during the computer simulation, current date and time.

J- In addition to the name of the field under study situated at the highest screen. 


\section{Tiger 2000 Grapher}

In general, the proposed grapher in the current study named Tiger 2000 Grapher draws pressure and production data over a time. According to Figure 9, the figure includes the drawing, the well and the coordinates of the reservoir. The data can be redrawn by changing the axis scale for the purpose of zooming in or zooming out. Tiger 2000 grapher also displays several pressure data types. The first type is the field measured pressure data used as a referenced data. The second pressure data type is the calculated pressure data for the current reservoir model, while the third pressure data type is the output results from other simulators (if they found). These data and results are directly plotted and presented simply and effortlessly allowing the engineer to visually make a comparison between the calculated results and measured field data, which is an important question and thus reduces the time of the engineer who spends much of time trying to extract suitable comparison by using other ready software. The Grapher Tiger 2000 extracts the data automatically as soon as it is turned on after the dynamic simulation period is over.

\section{2D Tiger 2000 Surfer}

The surface representation package represents the important reservoir data and results for each surface layer in two horizontal dimensions. These representations of data maps include:
A. Saturation distributions.
B. Pressure distributions.
C. Oil saturation distributions - porosity (oil storage).
D. Thickness distributions - permeability (zones of the most productive reservoir).
E. Thickness distributions.
F. Permeability distributions.
G. Porosity distributions.

These surface distributions maps mentioned above allow the engineer in charge to identify important areas and zones within the reservoir under study such as depleted zones that need to be strengthened or stimulated or the most promised productive zones. The proposed surfer in the current study named Tiger 2000 surfer is capable to redraw with more accuracy using the right hand side menu to choose (More Resolution) with the desired size and direction $\mathrm{x}$ or $\mathrm{y}$ or both. 2D Tiger surfer generates the following data presented with each drawing:
A. The period during which the distribution was found.
B. Time measured in days.
C. Layer under consideration measurements.
D. Type of data presented such as pressure, saturation, etc.
E. Right side menu to change resolution or to view the second distribution.
F. Colors scale and what they are actually represent.

\section{3D Tiger Surfer 3D Representation}

Three dimensional representations are a very important and useful especially in simulation which is at the same time requires a very large software effort. The 3D Tiger Surfer proposed in the current study represents the outputs and reservoirs in three dimensional animated view. This feature allows the engineer to walk through the reservoir and calculated results virtually from any level, angle and scale they desire. The three dimensional animation representation of calculated results and reservoir can be regarded as very powerful tool helps to detect the errors if they found and to suggest the proper solutions very easily.

3D Tiger 2000 surfer provides very large possibilities and many options. Some of these options are mentioned bellow:

A. Grid Dimension display in which the dimensions and number of the grid cells used to simulate the reservoir are displayed. 
B. View aspect settings to control the rotation angle ( 0 to 360 degrees) and zoom in and zoom out of the three dimensional shape and the level of visions (above, parallel or below the level of sight) and degree of resolution.

C. The type of data to be presented by which the engineer can choose the values to be represented such as pressure, saturation or any other type and there are many.

D. Under the option Data for Plotting, the data and time at which the calculations are chosen for the current layer.

E. Rotation Axis can be used as the axis around which the 3D shape rotates such as around the $x, y, z, x-$ $\mathrm{y}, \mathrm{x}-\mathrm{z}, \mathrm{y}-\mathrm{z}$ or $\mathrm{x}-\mathrm{y}-\mathrm{z}$ axis.

F. Cells of the layer can also be represented separately or connected by activating the Split Blocks option.

G. The water aquifer can also be represented or hidden through the View option.

\section{Reservoir Tiger Show}

In this package named in the current study Reservoir Tiger Show, the reservoir, the aquifer and the locations of the production and injection wells are represented. The Reservoir Show is considered as an efficient tool which allows the engineer to see the networks that represent the reservoir and its aquifer in three dimensional animations. These networks were previously can be just imagined as logical arrays and mathematical calculations only. Thanks to the stereoscopic vision of the reservoir provided by the current package, it is easy to inspect the network and what it represents of reservoirs, layers and a water aquifer, detecting the errors (if they are found) in a simple way and can be modified before continuing to the simulation phase. In the three dimensional representation of the reservoir there are several possibilities and figure 29 shows its main interface. Some of these are mentioned bellow:

A. Grid Dimension displays the dimensions and number of the grid cells used to simulate the reservoir.

B. View Settings in which the rotation angle (0 to 360 degrees) and zoom in and zoom out of the three dimensional shape, the level of visions (above, parallel or below the level of sight) and the degree of resolution.

C. Aquifer/Wells option enables to activate the water aquifer to be viewed. Wells can be represented by activating the View Wells option in which the red colored column represents production wells and the white colored column represents injection well.

D. The Show option can be chosen to view all layers or single layer.

\section{8. $\quad$ Printing and Reporting Output Package}

In this package, the processed and manipulated data and results can be printed in very easy manner. This Package offers all the options for printing and figure 36 shows the main menu of the package, which shows the following options:

A. Printing input data entry - porosity - permeability - Thickness - depths - well locations - network maps for each reservoir cell. This option serves as a feedback tool to check the data entry.

B. Print results - pressure for stable and dynamic period - saturations for stable and dynamic period.

C. Printing analyses such as porosity $\mathrm{X}$ saturation to detect the zones with greatest storage, permeability $\mathrm{X}$ thickness to detect the most permeable zones which are very important for future reservoir development.

The general hierarchy of the integrated simulation software package can found in Fig. (1).

\section{Verification and Validation}

The most two main important stages in constructing a model are verification stage and validation stage ${ }^{(1)}$. The verification stage concerns about the eliminating of the errors in the logical and mathematical structure of the 
model. While the validation stage led to make the proposed model represents the actual simulated case. To achieve these two stages, a field case is considered by the proposed integrated software package proposed in the current study. The general procedure for using the proposed software package Tiger 2000 through data entry and simulation can be shown in Fig. (2).

\section{Application - A Field Case}

The proposed integrated simulation software in the current study Tiger 2000 is applied to a field case. This field case is an oil reservoir field $(\mathrm{X})$ situated in the north sector of the Iraq southern part. The simulation process and some of the output results will be illustrated briefly in the following paragraphs.

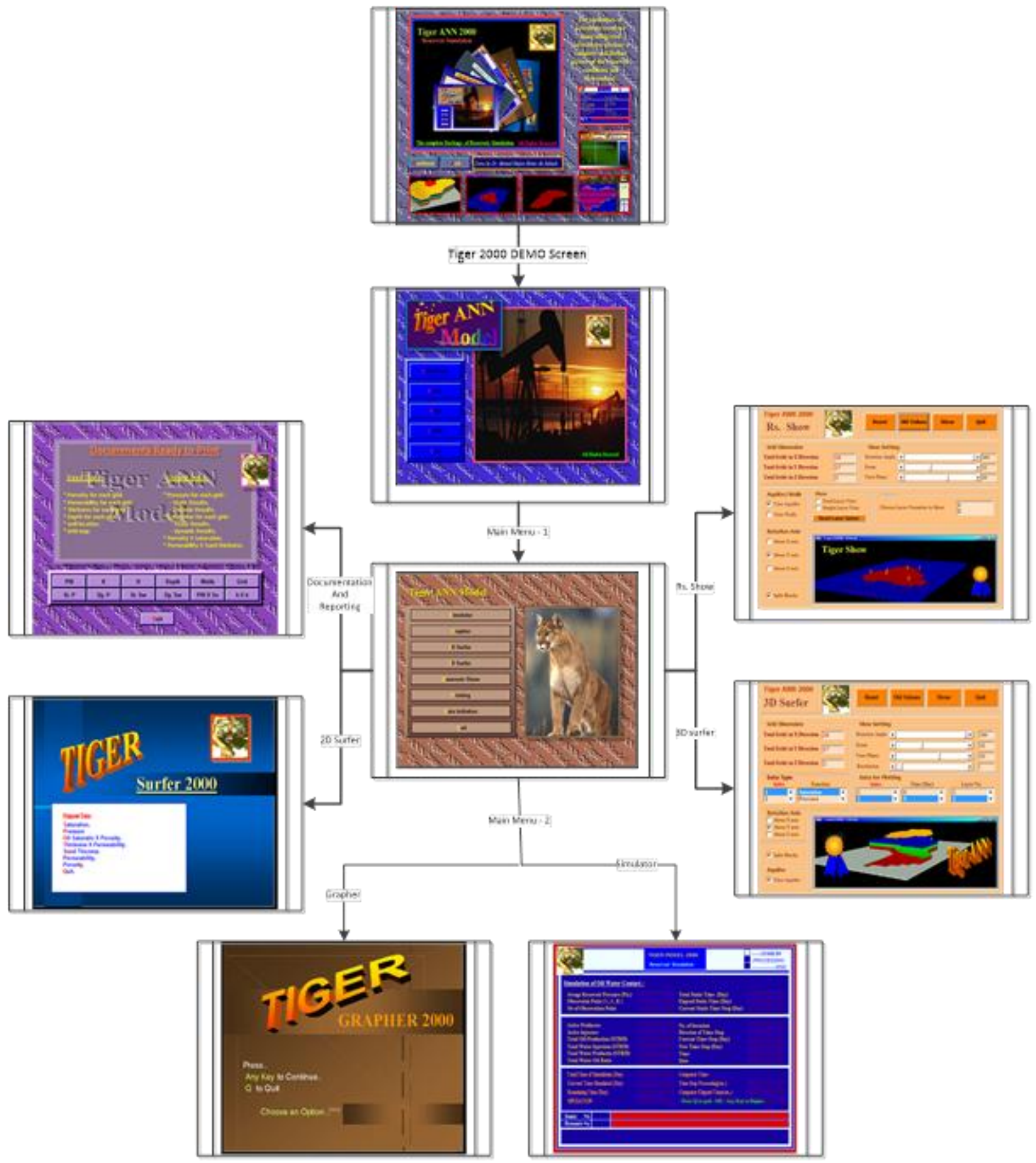

Figure 1. Tiger 2000 Integrated Software Package - General Hierarchy. 


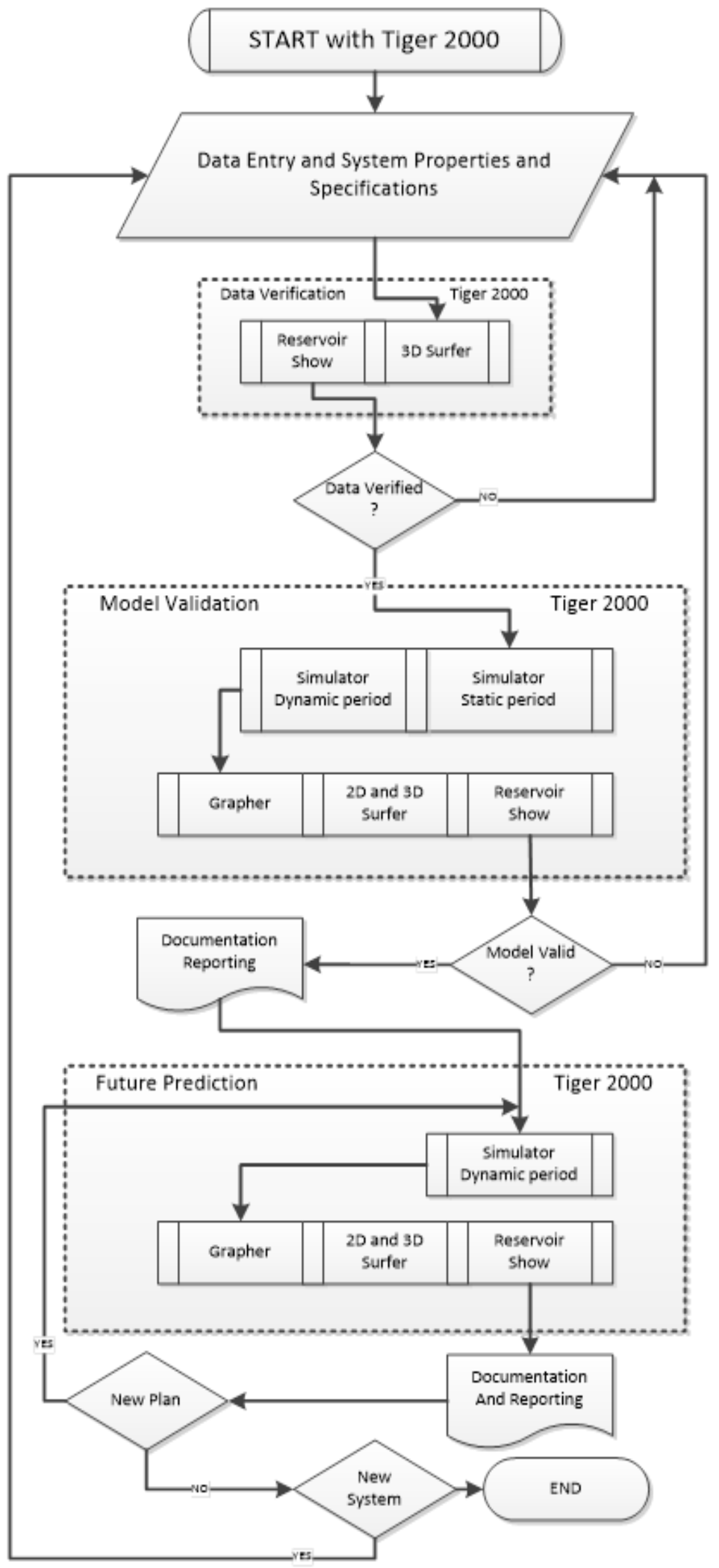

Figure 2. Tiger 2000 - General Simulation Procedure Flow Diagram. 
The beginning of simulation process in static stage reservoir initialization (about 36\%) can be shown in Fig.(3). In this figure, an observation point situated in cell of $\mathrm{i}=5, \mathrm{j}=5$, and $\mathrm{k}=1$, this observation point serves as a referenced feedback point to control the static stage. The simulation process of the considered reservoir dynamic stage is illustrated in Fig.(4). This stage begins after the static stage and which represents the actual simulation process. From Fig.(4), it can be seen that many important data and results are displayed simultaneously during the simulation process which makes the operator informed by all the important events occurred and resulted during the process of simulation. The end of dynamic simulation process can be found in Fig.(5) which occurred at about 2500 days for this considered reservoir. A sample of Tiger 2000 grapher can be seen in Fig.(6) in which the measured pressure history of well No. 5 are compared with calculated pressure results by Tiger 2000 Simulator for the same well. Also in the same figure, it can be found the oil production flow rate for well No. 5. While Fig.(7) represents the same data but for well No. 6. One of important things in Tiger 2000 Grapher is that these graphs are plotted automatically as soon as the dynamic simulation stage is finished and instantly as

The grapher is opened depending on the newest simulator outputs. This well reduces the judgment and decision making time to a very short limit as mentioned previously. A sample of Tiger 2000 2D surfer can found in Fig.(8) in which the saturation distribution for layer No. 1 and at dynamic simulation process time 1015 days while the Fig.(9) is the same data presented in figure (8) but with more resolution. Figure (10) represents the pressure distribution for layer No. 1 during dynamic simulation process at time 519 days and the Fig.(11) represents the same data but with more resolution. The initial oil storage (i.e. at zero time of dynamic simulation process) for layer No. 1illustrated in Fig. (12).

The three dimensional representation of saturation for layer No.1 is can be shown in Fig.(13) while Fig.(14) shows the same data of Fig.(13) but with different view angle. Figure (15) illustrates the three dimensional representation of saturation for layer No.1 but without its aquifer (view aquifer not activated). As mentioned early, the cells constructing the grid layer can be represented as separated or connected and Fig.(16) shows the connected cell view for layer No. 1 with same data in Fig.(15). The pressure distribution of layer No.1 in three dimensional view can be found in Fig.(17) with no activated view aquifer option. Figure (18) shows the grid cells and dimension in a three dimensional view for layer No.1 which most important for the engineer in charge to verify the input data and begin the simulation process correctly. Figure (19) shows the same data of Fig.(18) but without the aquifer of layer No.1. The three dimensional animation of the two layers composed the reservoir (Layer No.1). 


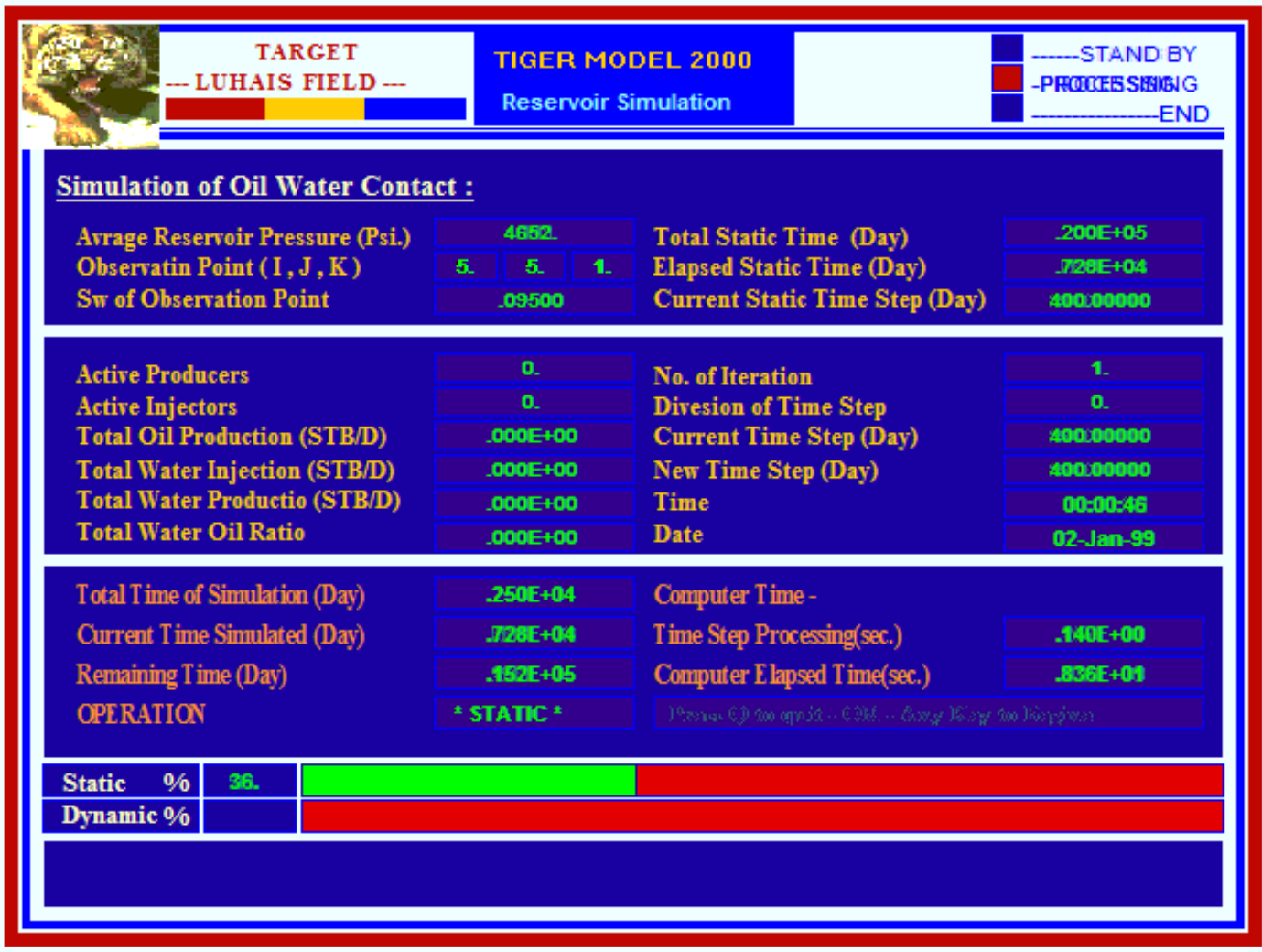

Figure 3. Simulator-Static simulation process (Data and model verification).

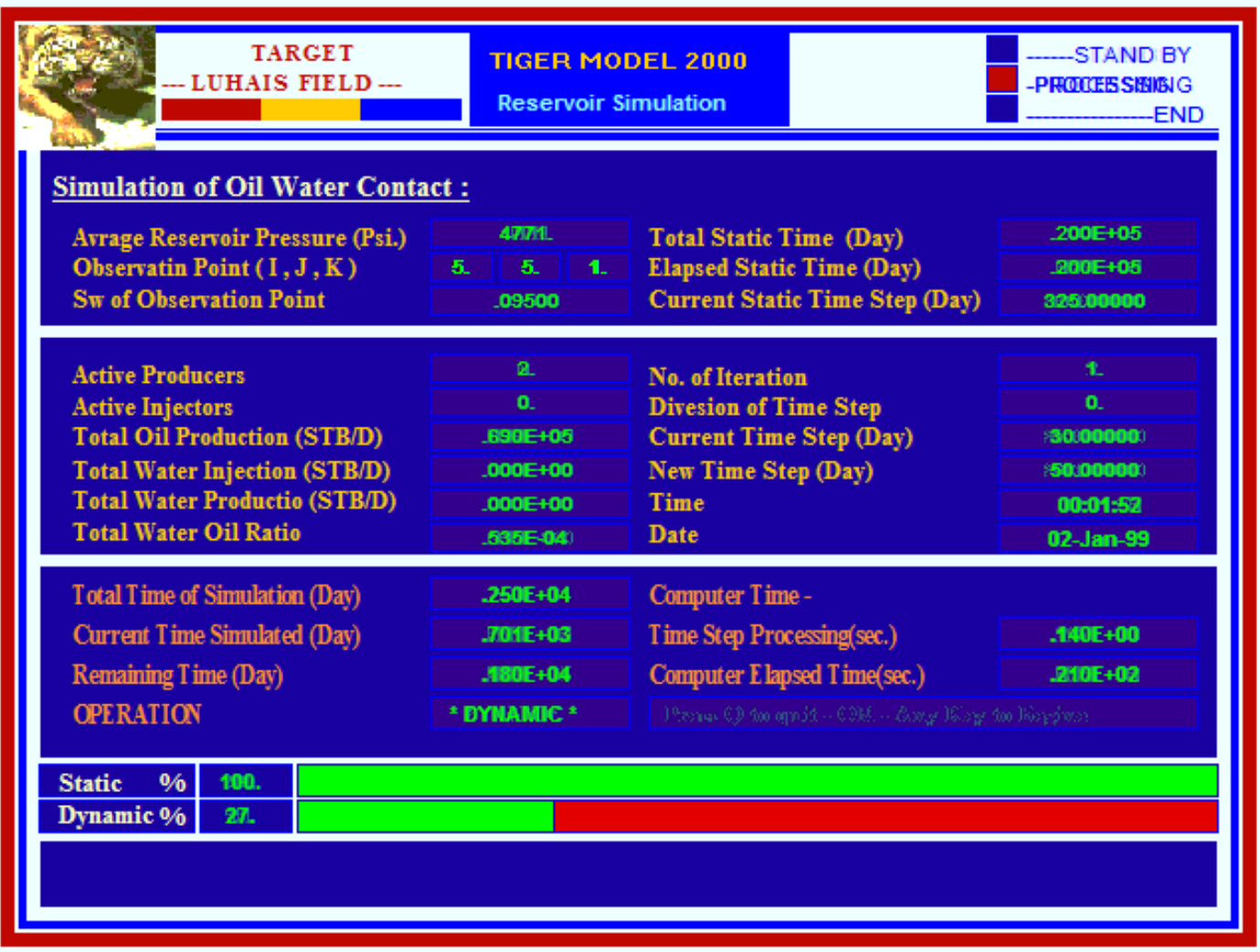

Figure 4. Simulator-Dynamic simulation process during simulation time. 


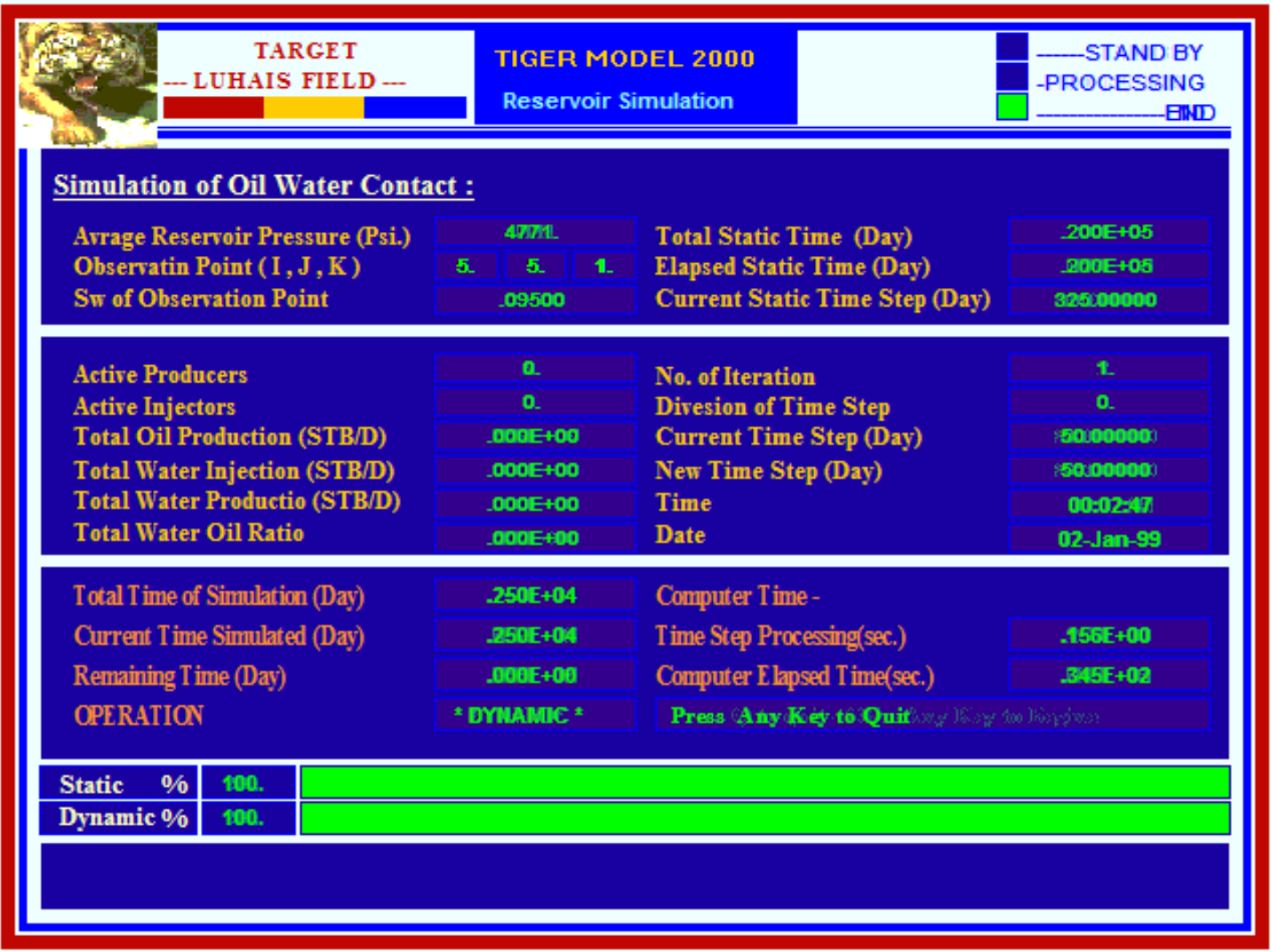

Figure 5. Simulator-Dynamic simulation process at the end simulation time.

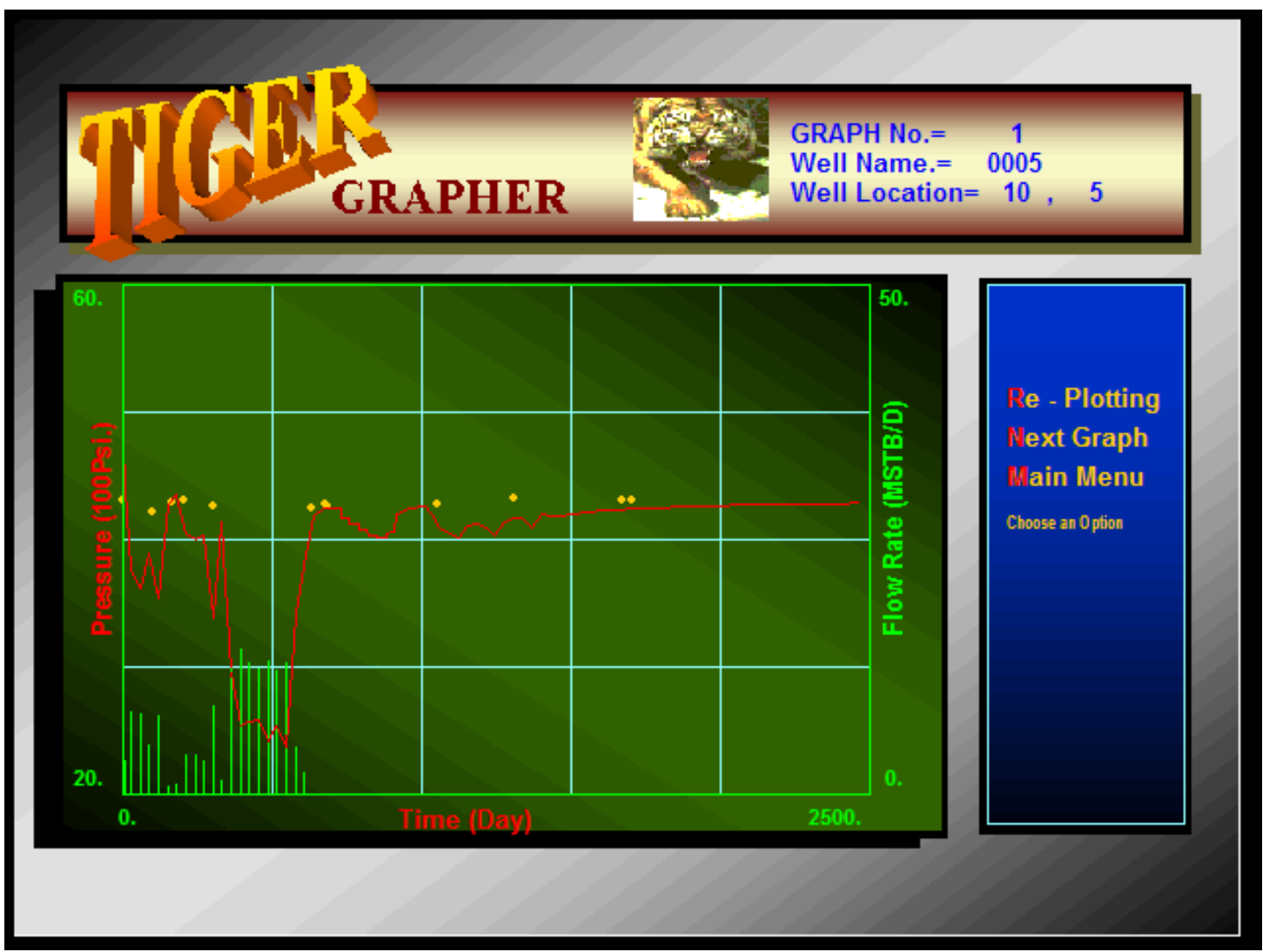

Figure 6. Grapher-Measured and calculated pressure at well 005 Dynamic operation. 


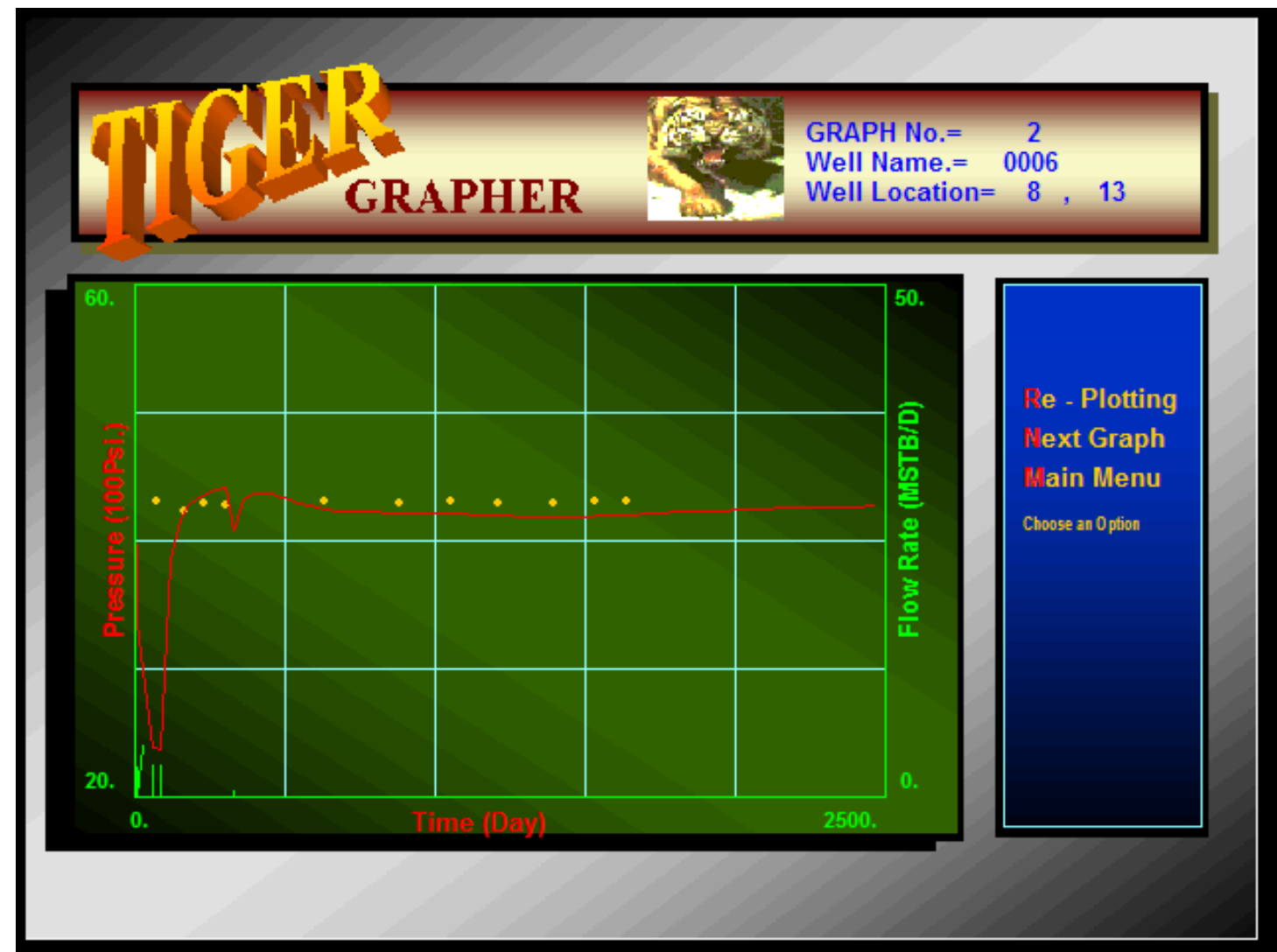

Figure 7. Grapher-Measured and calculated pressure at well 006 Dynamic operation.

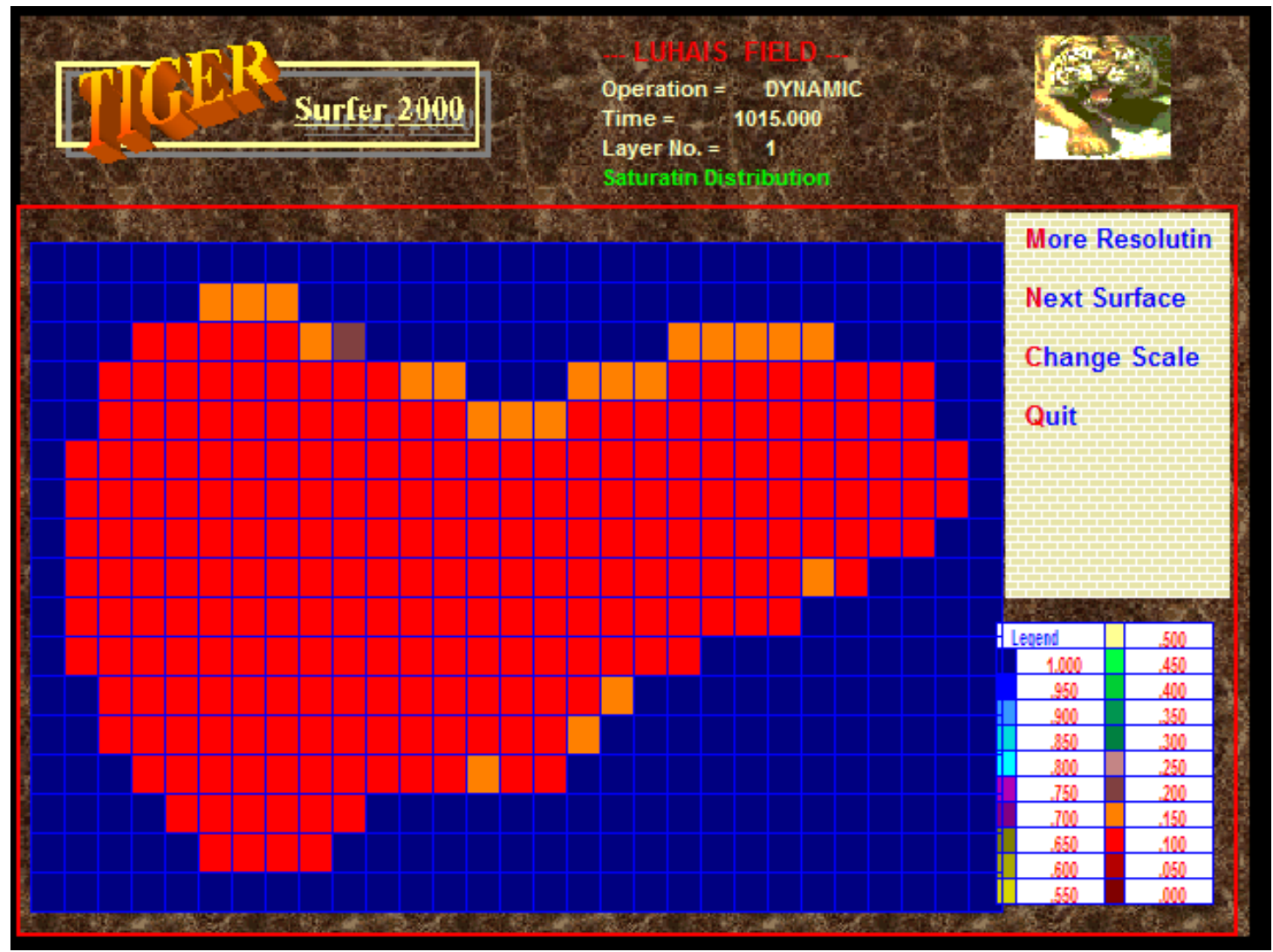

Figure 8. 2D Surfer- Saturation Distribution Layer No.1 Dynamic operation. 


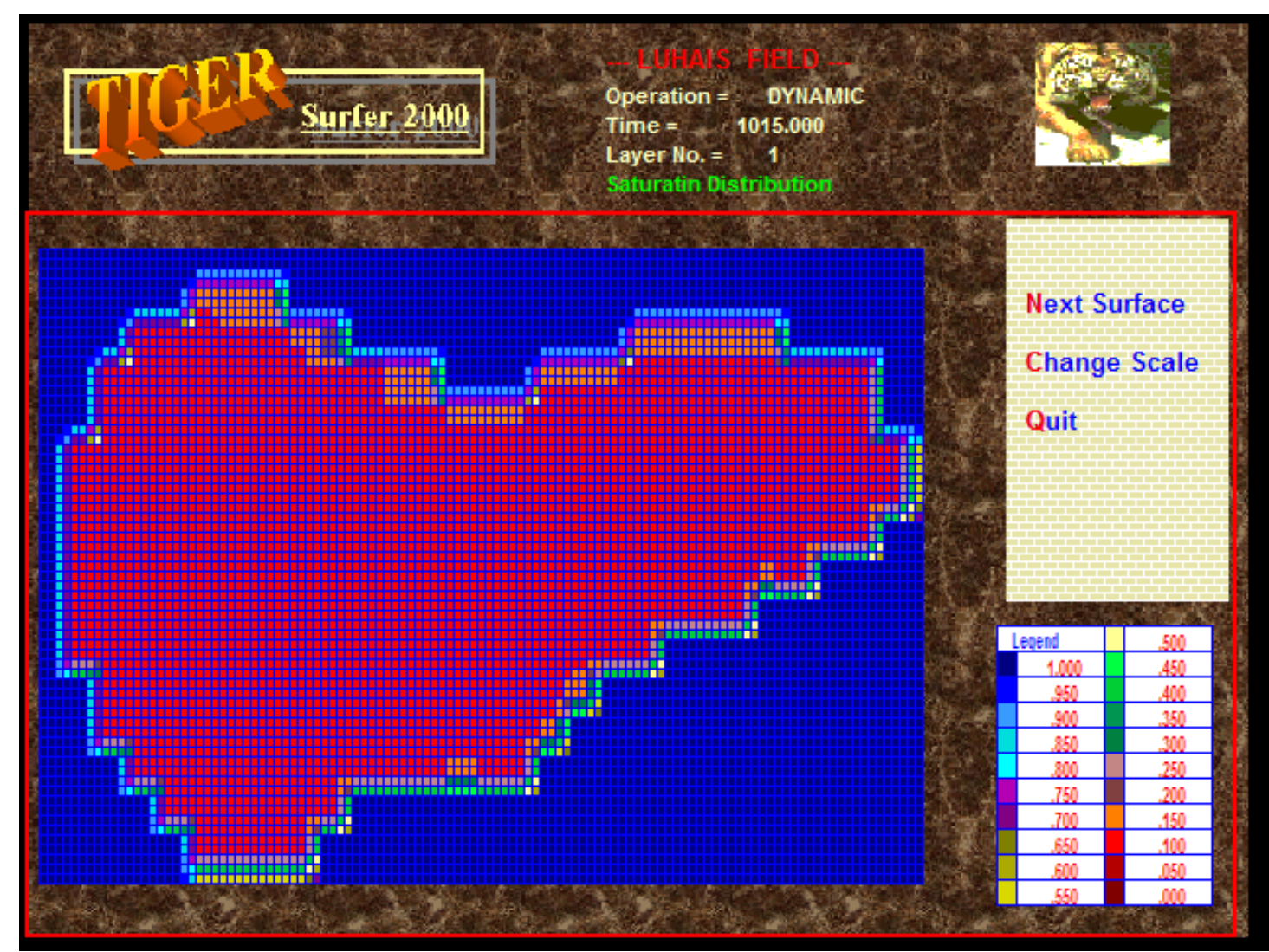

Figure 9. 2D Surfer-Saturation Distribution. (Figure () with more resolution).

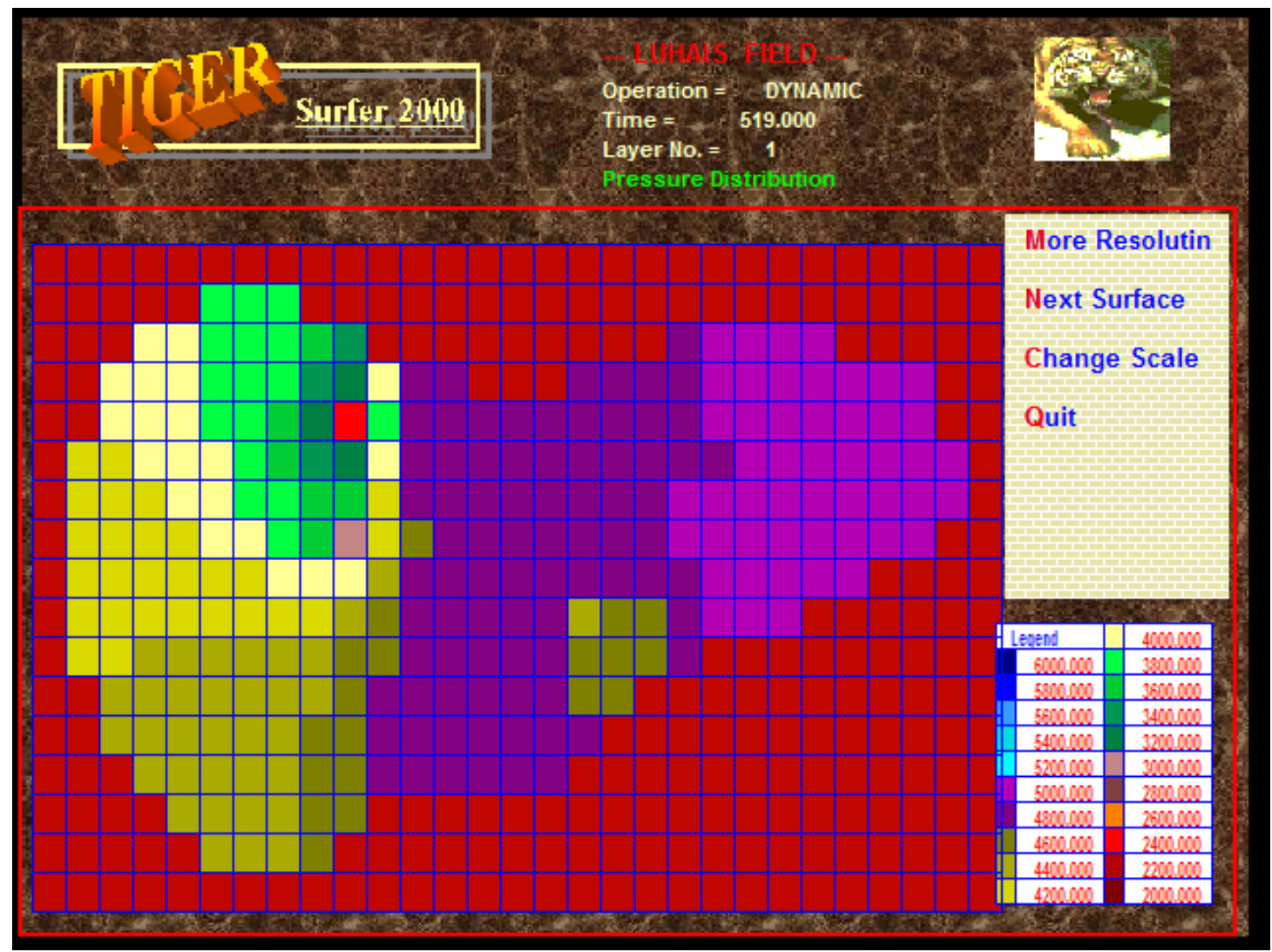

Figure 10. 2D Surfer- Pressure distribution Layer No. 1 Dynamic operation. 


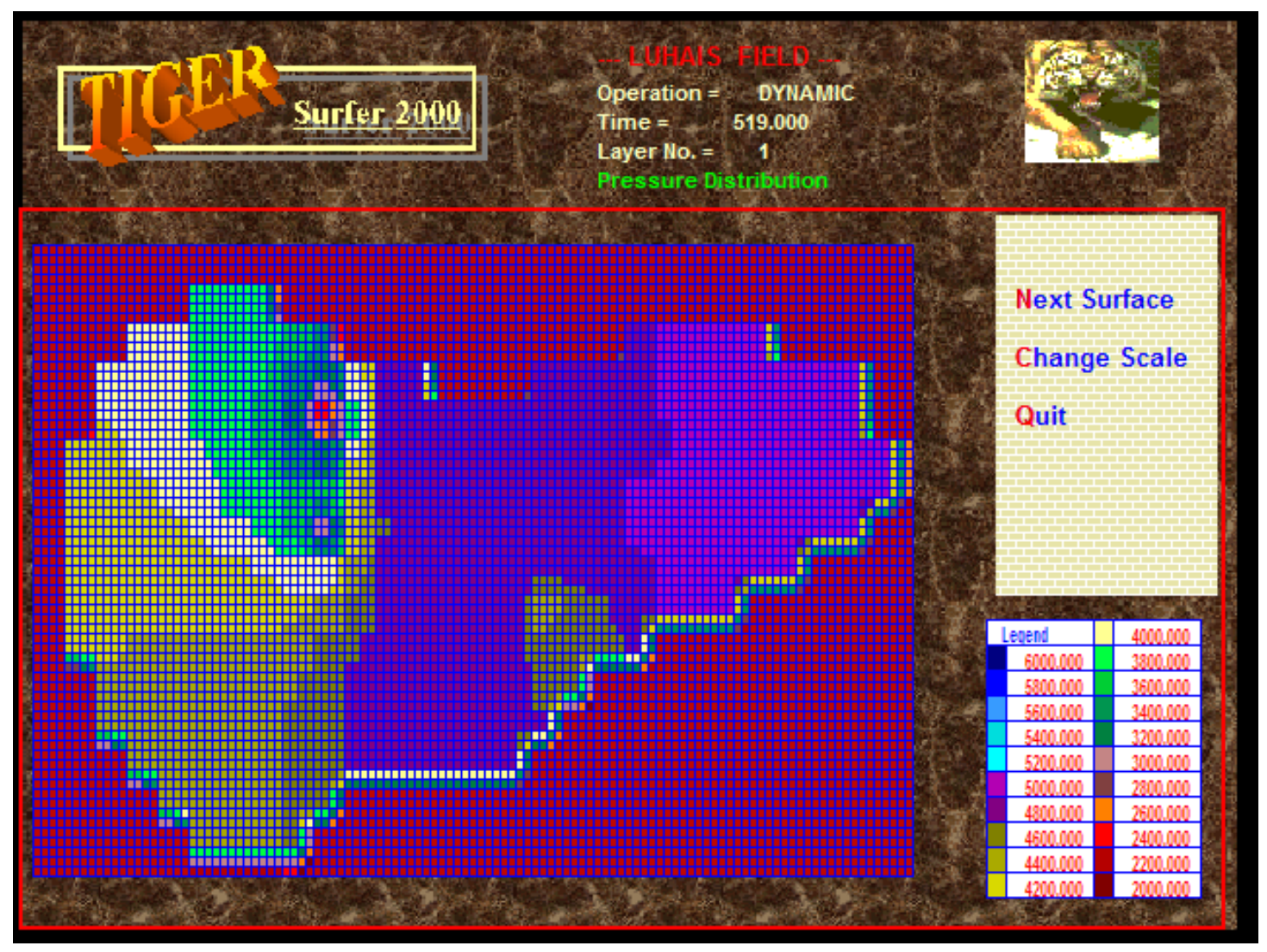

Figure 11. 2D Surfer-pressure Distribution. (Figure () with more resolution).

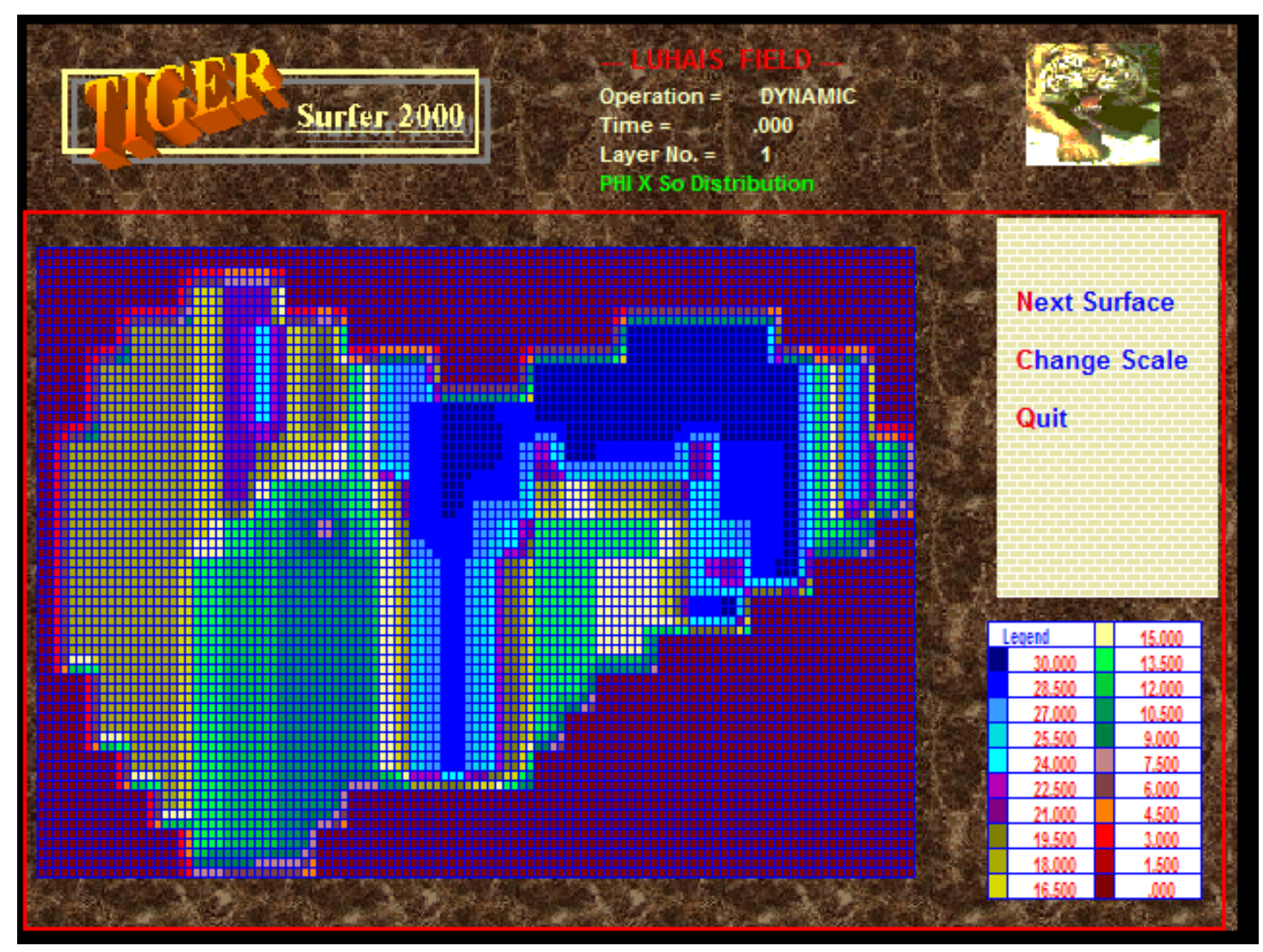

Figure 12. 2D Surfer- Porosity X Oil saturation Layer No.1 at zero time simulation. 


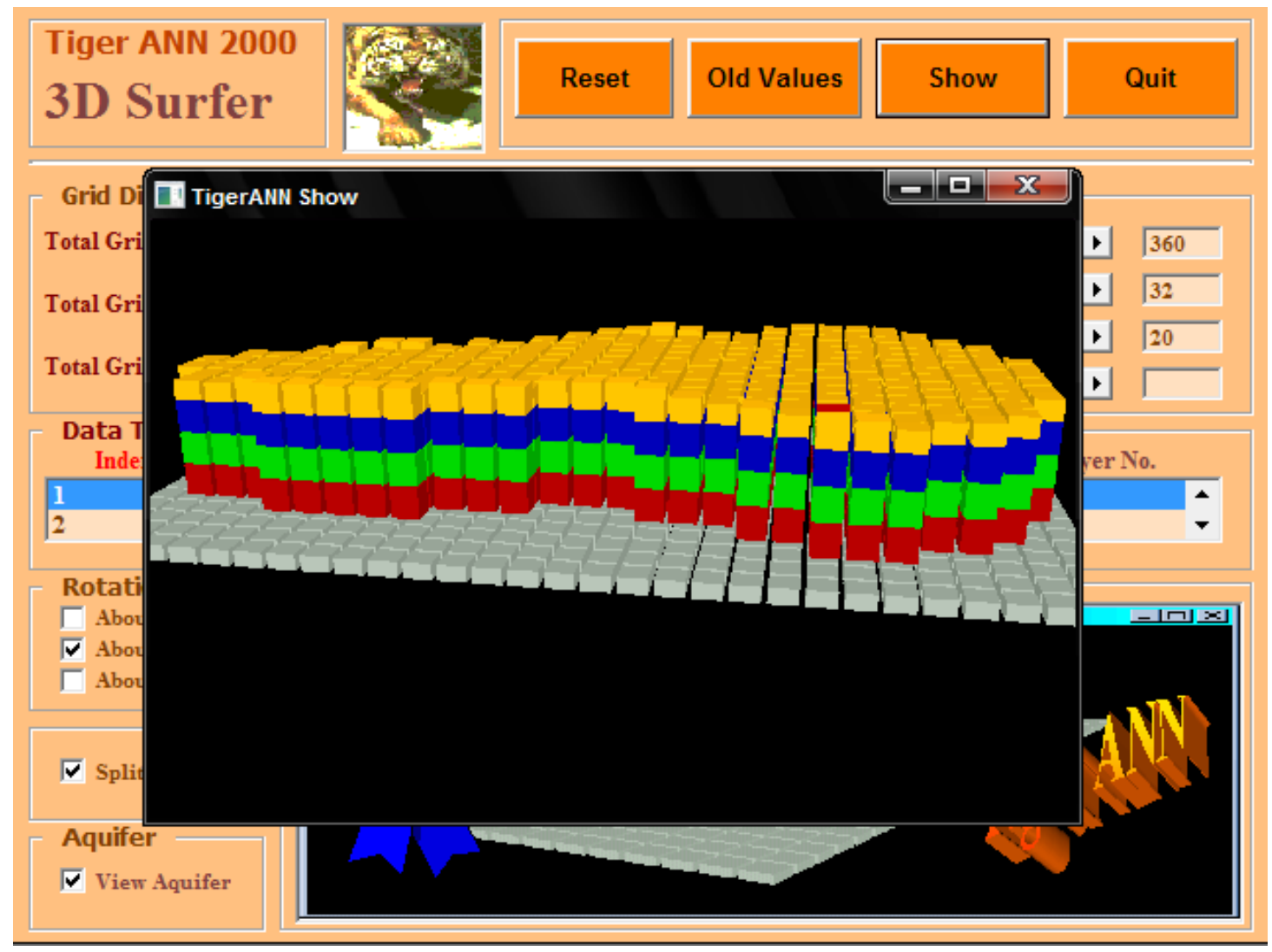

Figure 13. 3D Surfer- Pressure distribution- Layer No.1.

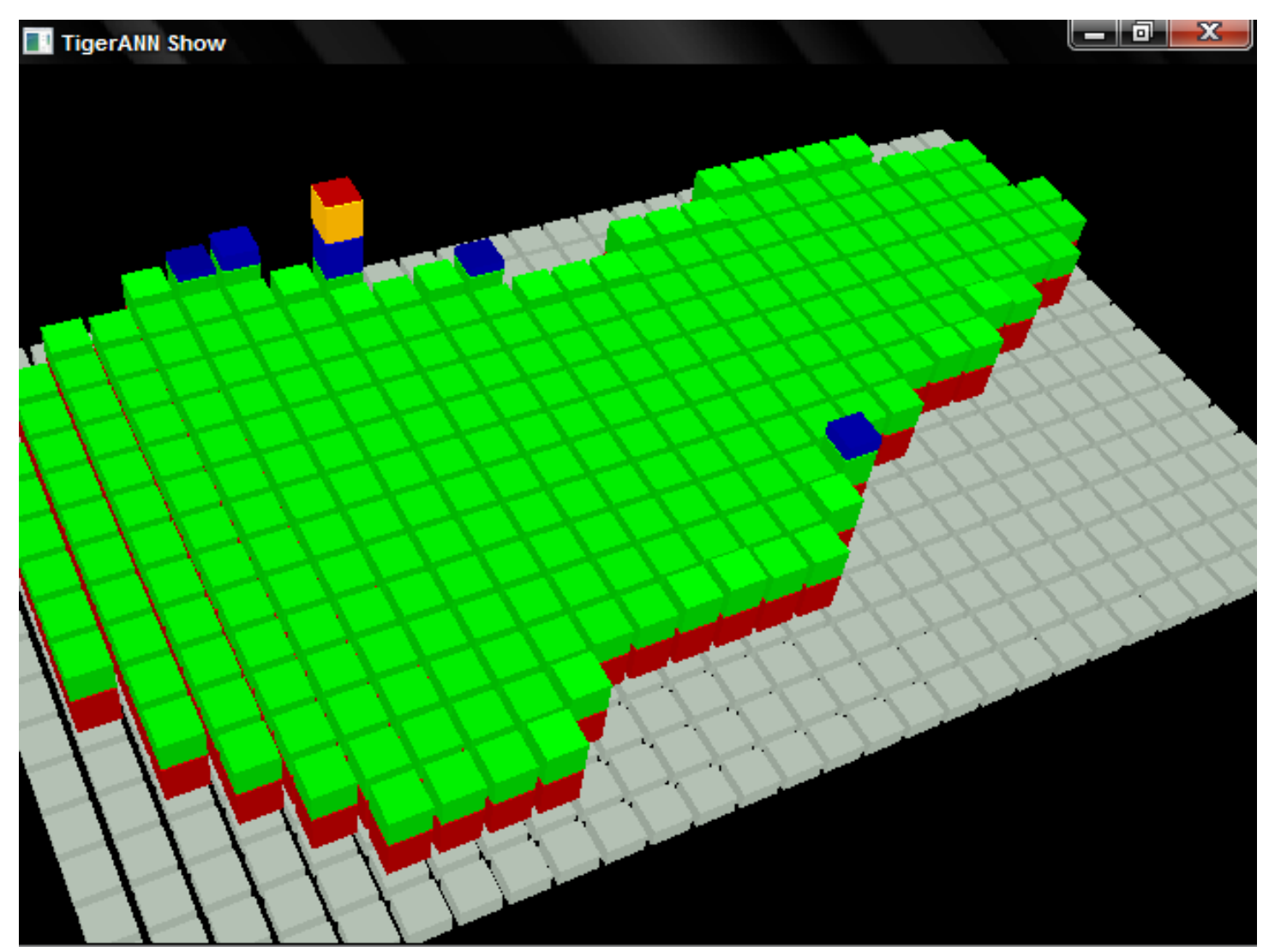

Figure 14. 3D Surfer- Pressure distribution-layer No.1. (Different angle of view). 


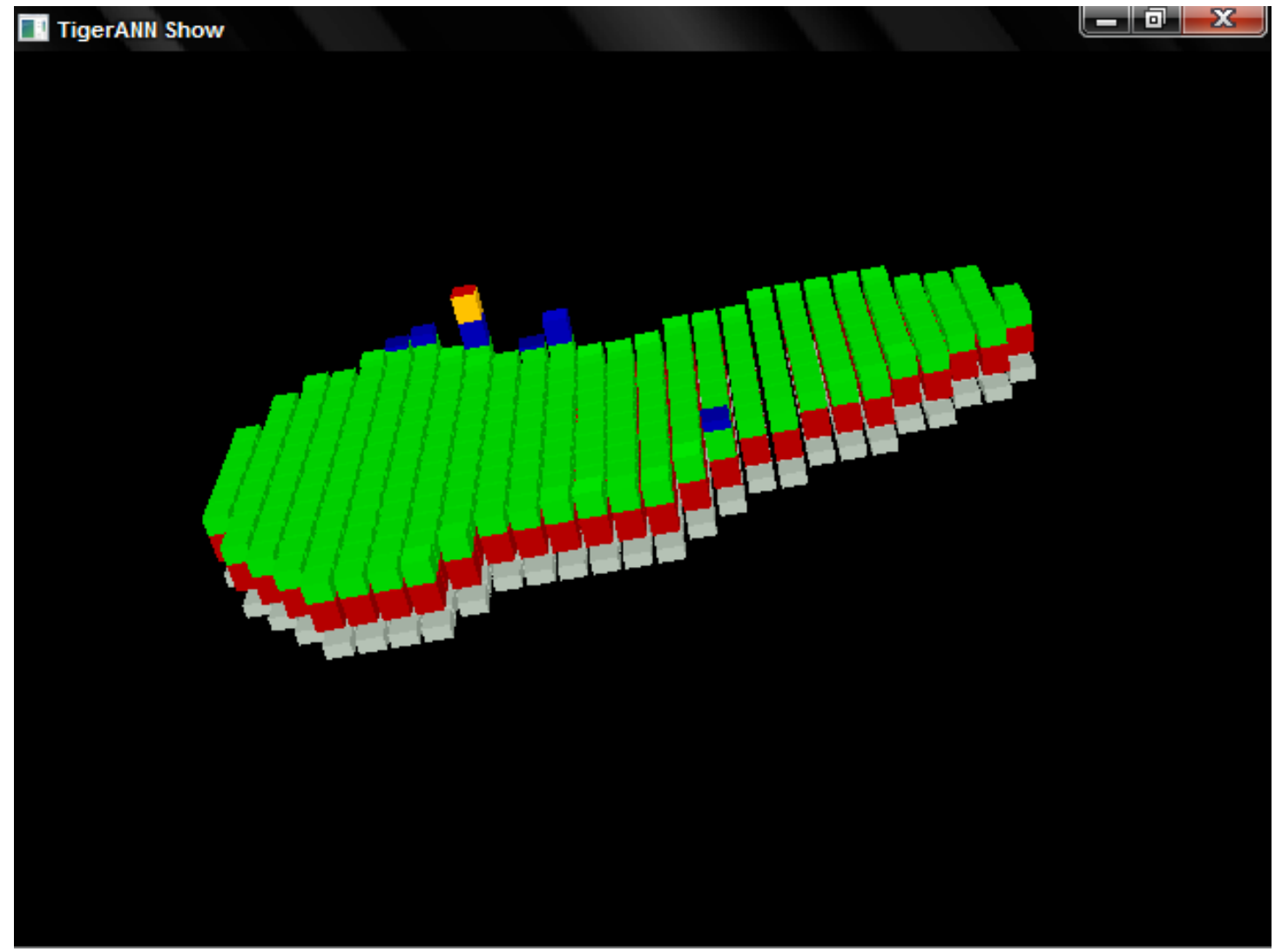

Figure 15. 3D Surfer- Pressure distribution-layer No.1. (Separated cells).

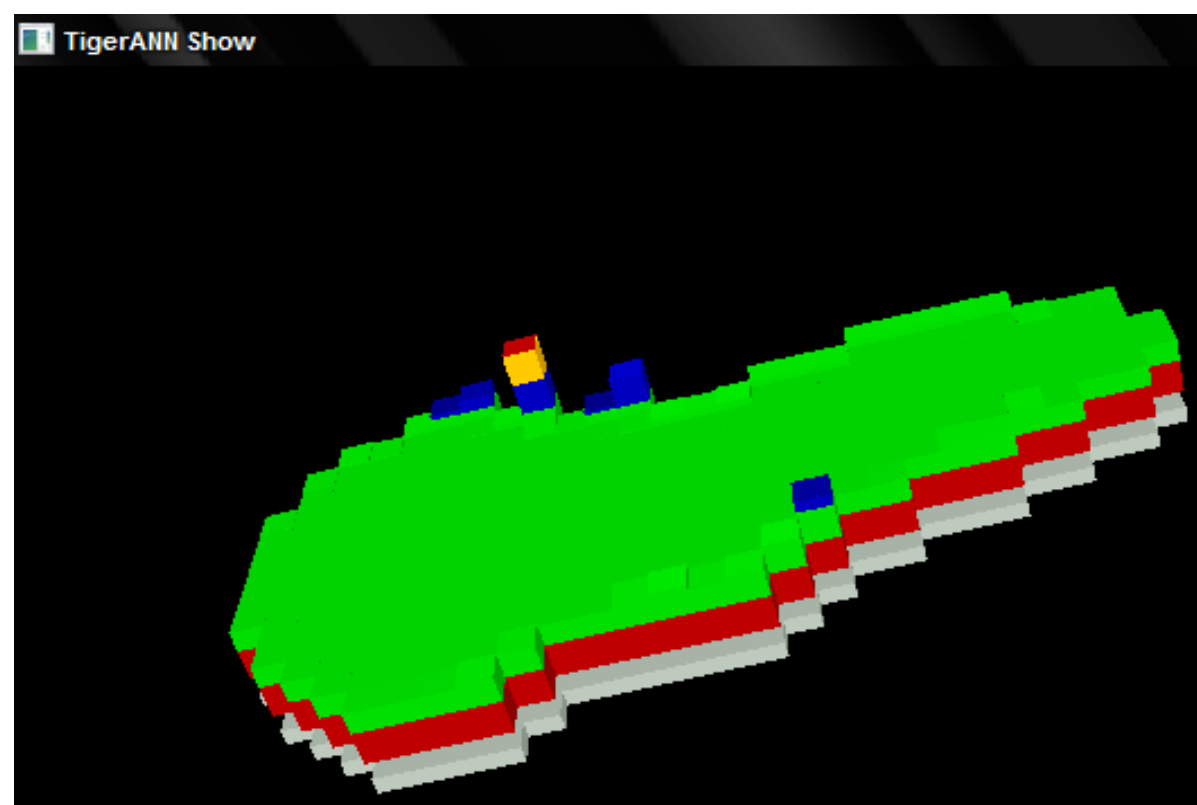

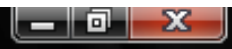

Figure 16. 3D Surfer- Pressure distribution-layer No.1. (Connected cells). 


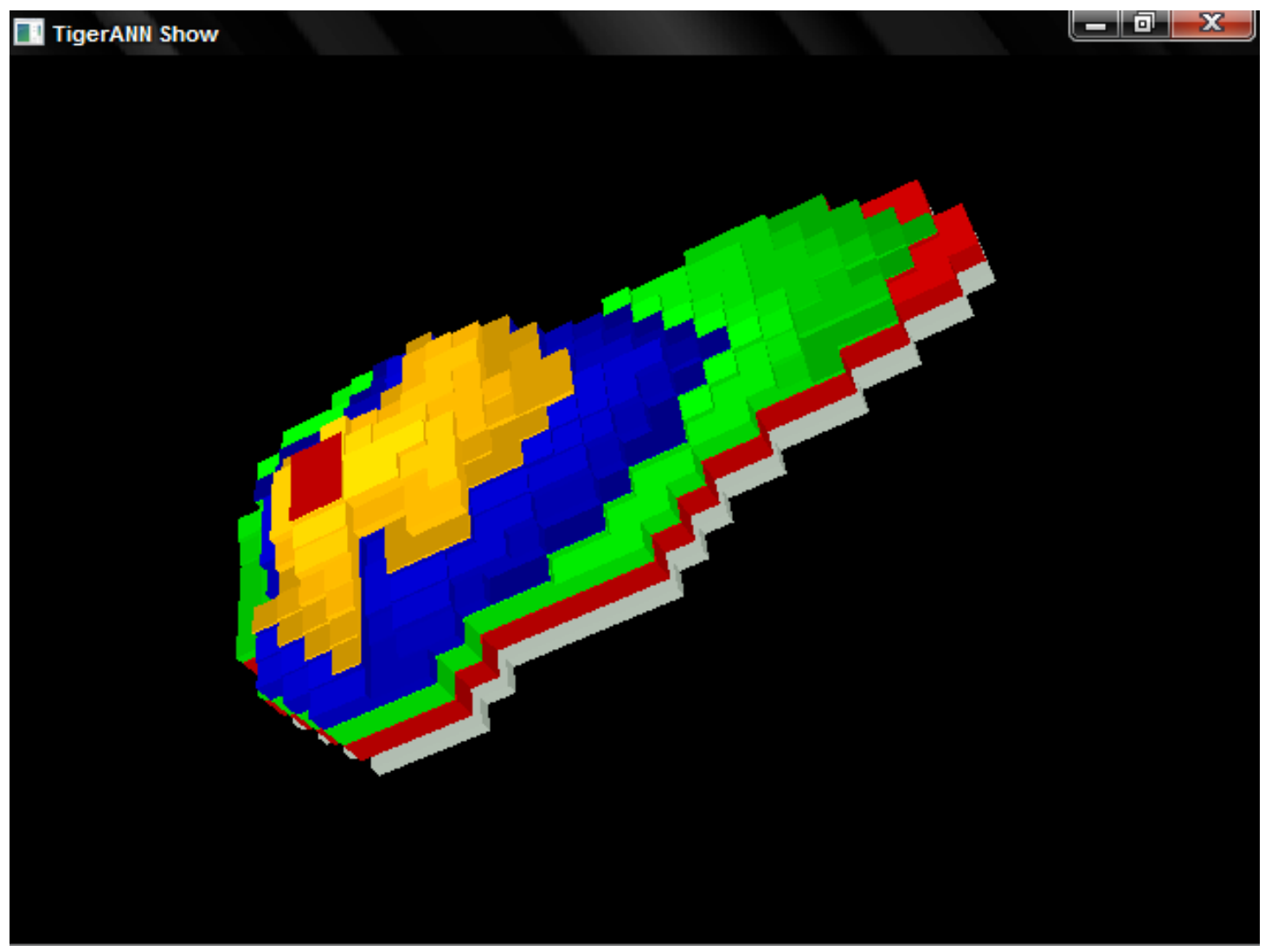

Figure 17. 3D Surfer-Saturation Distribution Dynamic operation-Layer No. 1.

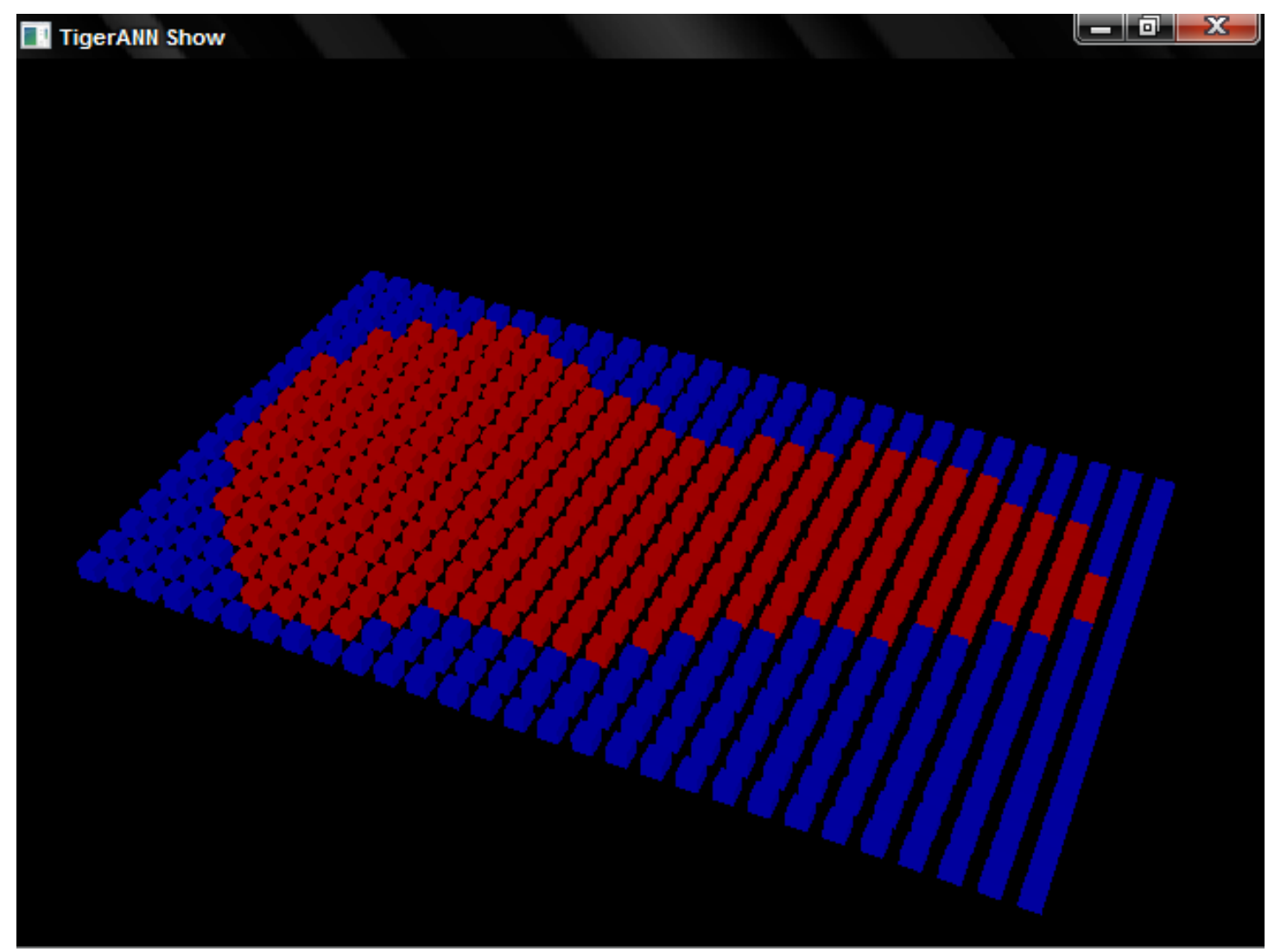

Figure 18. Reservoir Show- Layer No. 1 with its aquifer. 


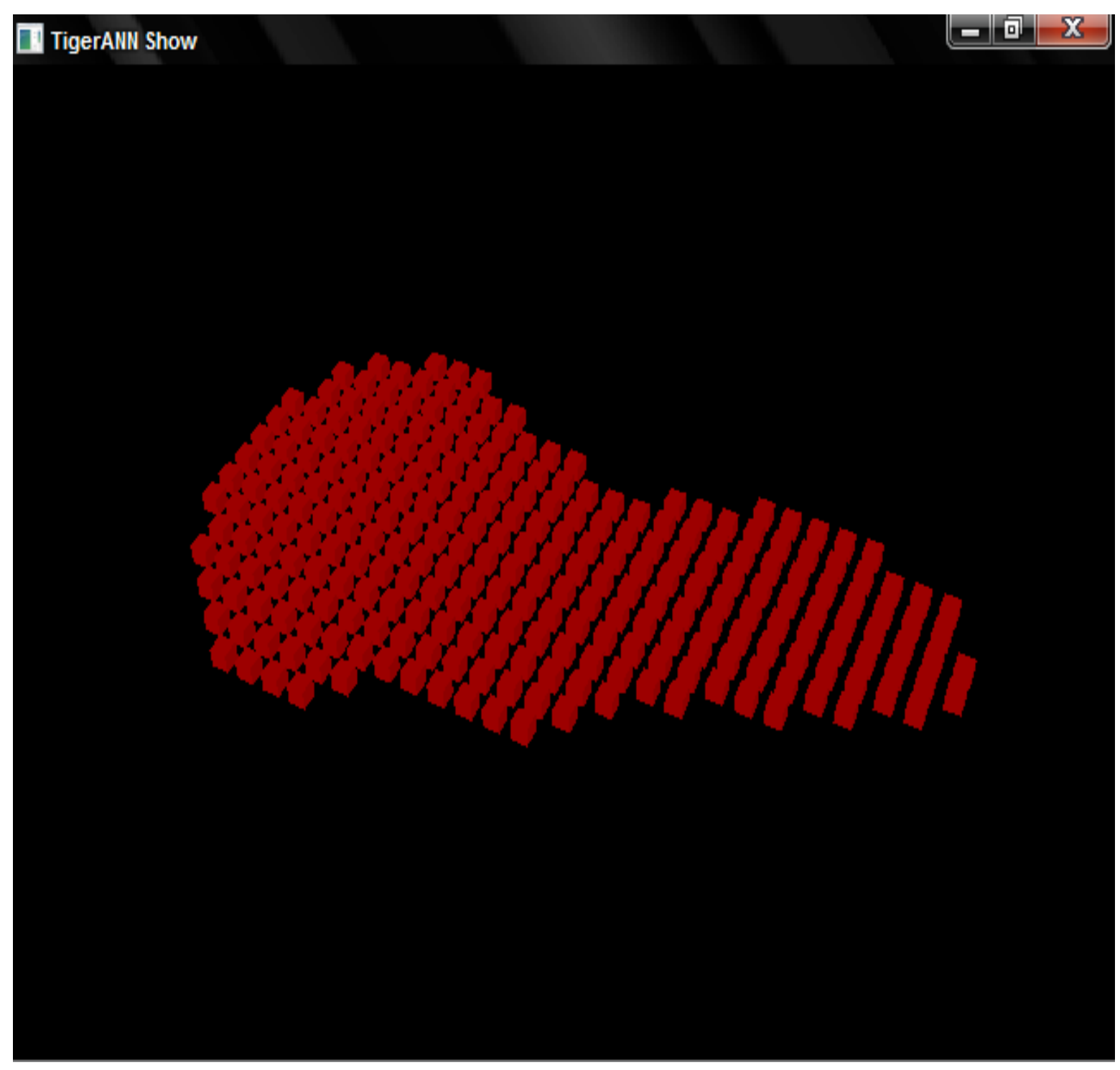

Figure 19. Reservoir Show- Layer No. 1 without its aquifer.

And (Layer No.2) can be seen in Fig. (20) While Fig.(21) shows the same layers but with well locations. As mentioned previously, these features make the studying and imagination of the considered system very easy and straight forward.

Actually there are a lot of output results with many options of representation but it can be illustrated all here. From the previous abbreviated introduction to the integrated software package Tiger 2000 proposed in the current study, it can be concluded that this software package capable to simulate different systems with different conditions and environments in oil industry or ground water resources aspect. It generates wide variety of output results and presentations to inform the engineer in charge about all basic and advanced operations and variables and helping him to make a decisions with more easily and simplest way. 


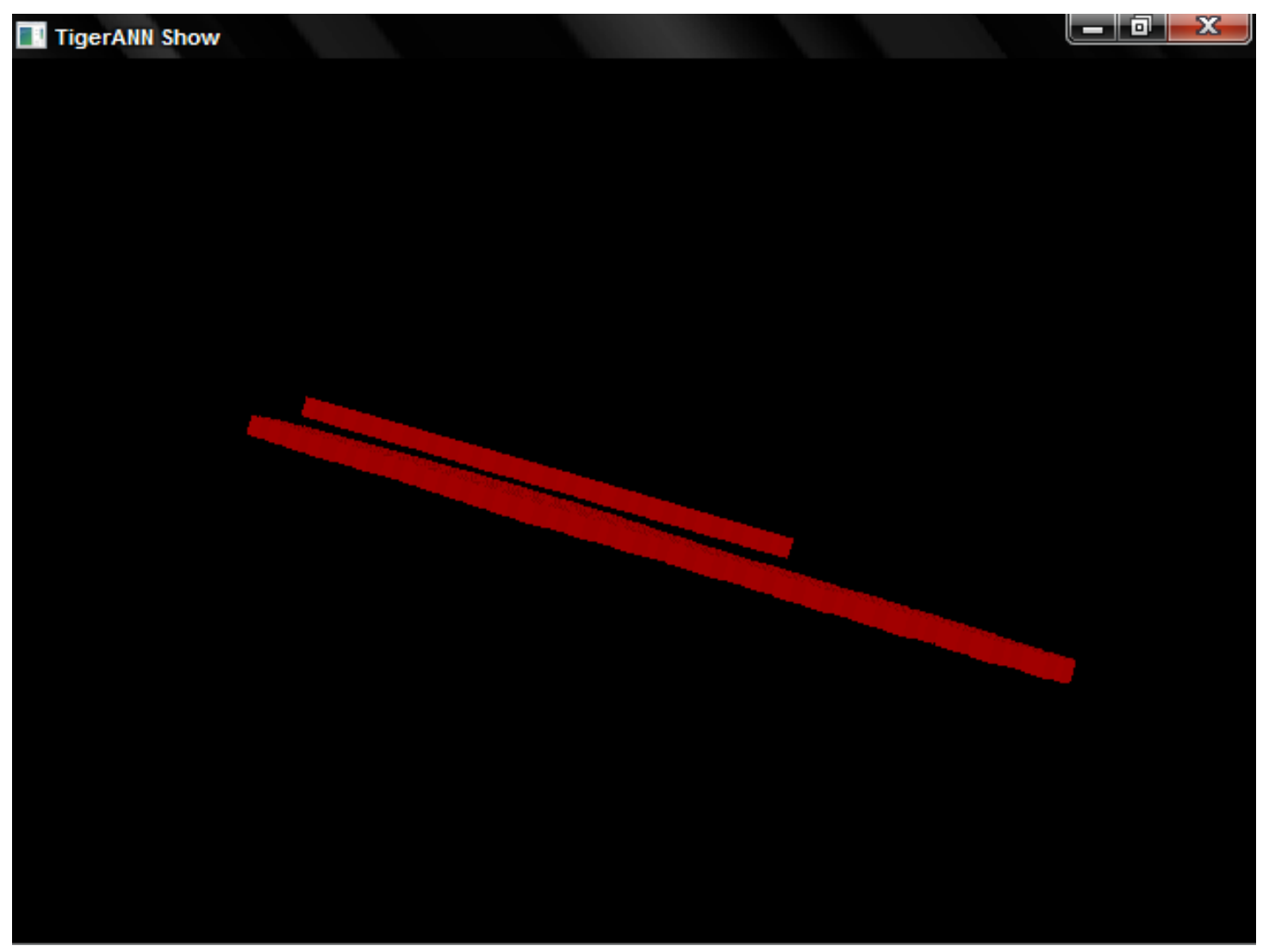

Figure 20. Simulation process during the static period (Data and model verification).

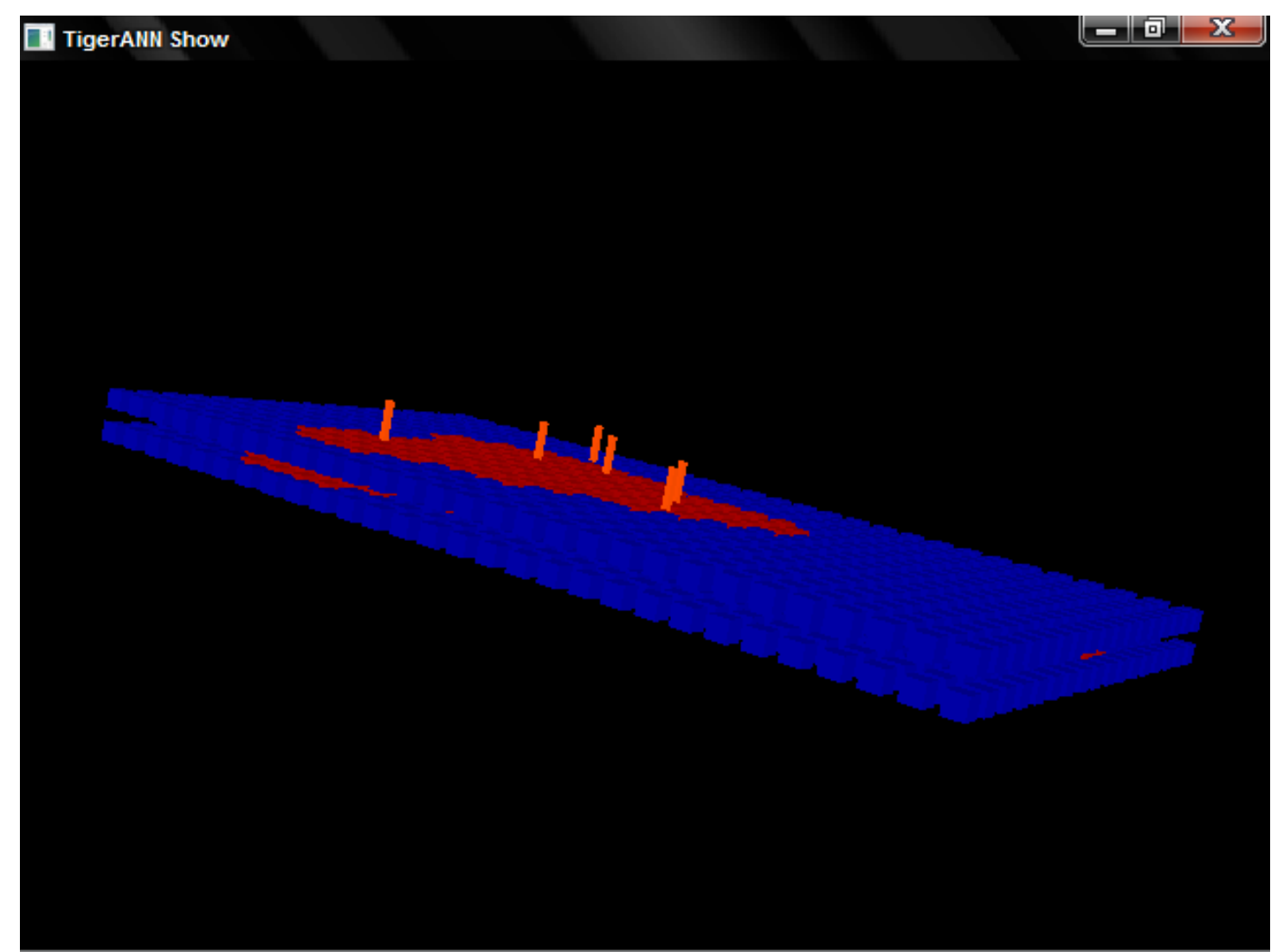

Figure 21. Reservoir Show-The whole reservoir and aquifer with well locations. 


\section{References}

[1] Erry Banks et.al. Discrete - Event System Simulation, Pearson, Fifth Edition, 2010.

[2] AzAziz, K. and Settari, A., Petroleum Reservoir Simulation, Applied science publishers, LTD, London, 1979.

[3] Kip Irvine and Tony Gaddis, Advanced visual basic, Addison Wesley, 2012.

[4] Advanced Visual Programming, Rai Technology University,

[5] DIGITAL Visual Fortran Programmer's Guide, Digital Equipment Corporation, 1998.

[6] Intel FORTRAN Compiler User and Reference Guides, Document Number: 304970-006US, 2001.

[7] Hans Petter Langtangen and Xing Cai, Mixed Language Programming for High-Performance Computing Applications

[8] Carsten A. Arnholm, Mixed language programming using C++ and FORTRAN 77, A portable technique for Windows NT/95, UNIX and other systems, Massachusetts, Version 1.1, 1998.

[9] Tom McReynolds, Advanced Graphics Programming Techniques Using OpenGL, Silicon Graphics, 1998.

[10] Abdullah Hasan Jabbar, Maytham Qabel Hamzah, Salim Oudah Mezan, Amira Saryati Binti Ameruddin, Mohd Arif Agam, (2018). "Green Synthesis of Silver/Polystyrene Nano Composite (Ag/PS NCs) via Plant Extracts Beginning a New Era in Drug Delivery" Indian Journal of Science and Technology, 11(22), pp: 1-9.

[11] Dave Shreiner et.al. OpenGL Programming Guide, Addison Wesley, Eighth Edition, 2013.

[12] Crichlow, H.B, Modern Reservoir Engineering - A Simulation Approach, Prentice- Hall, Inc. New Jersey, 1997.

[13] Paceman, D.W., Fundamentals of Numerical Reservoir Simulation, Elsevier Sci. Pub. Co., 1977.

[14] Ahmed N. Nimir Al-Sabeeh, Sectorial Study of Water Front Advancement in North Rumaila Oil Field, Ph. D. Thesis, Baghdad University, 2000. 